\title{
ES DIFERENTE LA ELECTROENCEFALOGRAFÍA TRAS LA CON INDUCCIONES RÁPIDAS O LENTAS? ¿QUÉ NOS DICE EL ESPECTROGRAMA CLÍNICO?
}

\author{
Pablo Sepúlveda V. ${ }^{1}$, Ignacio Acosta ${ }^{2}$, Esperanza Carrasco ${ }^{1}$, Arnold Hoppe ${ }^{2}$ \\ Clínica Alemana Santiago, Servicio Anestesia. \\ 2 Clínica Alemana Santiago, Servicio Neurología.
}

Introducción: En la inducción anestésica rápida, la mezcla de la droga es inestable, y si bien el paciente puede perder conciencia rápido, la condición basada en la aparición de una estable e intensa banda alfa $(8$ a $13 \mathrm{~Hz})$ frontal $^{1}$, que se ha aceptado como definidor del estado anestésico de propofol, puede tardar en instalarse.

Objetivo General: El objetivo de este estudio es comparar el poder espectral y el curso temporal de la instalación de este patrón en inducciones lentas o rápidas usando datos de un espectrograma frontal.

Material y Métodos: Ensayo clínico experimental y randomizado aprobado por Comité de Ética y consentimiento informado, incluyó adultos ASA I- II, sin enfermedades neurológicas y con examen físico normal. Los pacientes fueron randomizados en dos grupos, GR (inducción rápida) con propofol en TCI efecto modelo Marsh ke0 1,21 $\mathrm{min}^{-1}$ a una diana calculada a la biofase de $5,4 \mathrm{ug} / \mathrm{ml}(\mathrm{EC} 95)^{3}$ y GL (inducción lenta) con propofol a $10 \mathrm{mg} / \mathrm{kg} / \mathrm{h}$ basados en CeCALC mismo modelo cinético. Se utilizó monitoreo estándar y EEG SEDLINE. Tras la pérdida de la conciencia (LOC) evaluada por Neurólogo usando escala de $\mathrm{FOUR}^{3}$ (E0 ausencia de apertura ocular y/o M0 sin respuesta motora), se mantuvo por $10 \mathrm{~min}$ en GR la diana $5,3 \mathrm{ug} / \mathrm{ml}$ y en GL la Ce al LOC. Los datos de los 4 canales EEG frontales crudos extraídos de monitor SEDLINE vía usb se procesaron con edf + (Polyman). Tras identificar en cada paciente la banda alfa (8-13 $\mathrm{Hz}$ ) del EEG, desde 1 min antes de LOC hasta 10 min posteriores, se procedió a estandarizar por individuo el poder espectral de alfa $(\mathrm{zdB}=\mathrm{dB}$ promedio/dst) y se compararon esos valores con T test por tipo de inducción y por cada minuto.

Resultados: Se incluyeron 8 pacientes por grupo comparables en edad, peso y talla. La mediana del tiempo en alcanzar el LOC fue 682 (330 -1.140) seg en GL y 93 (60 - 210) seg para GR. La mediana de la Ce CALC al momento del LOC

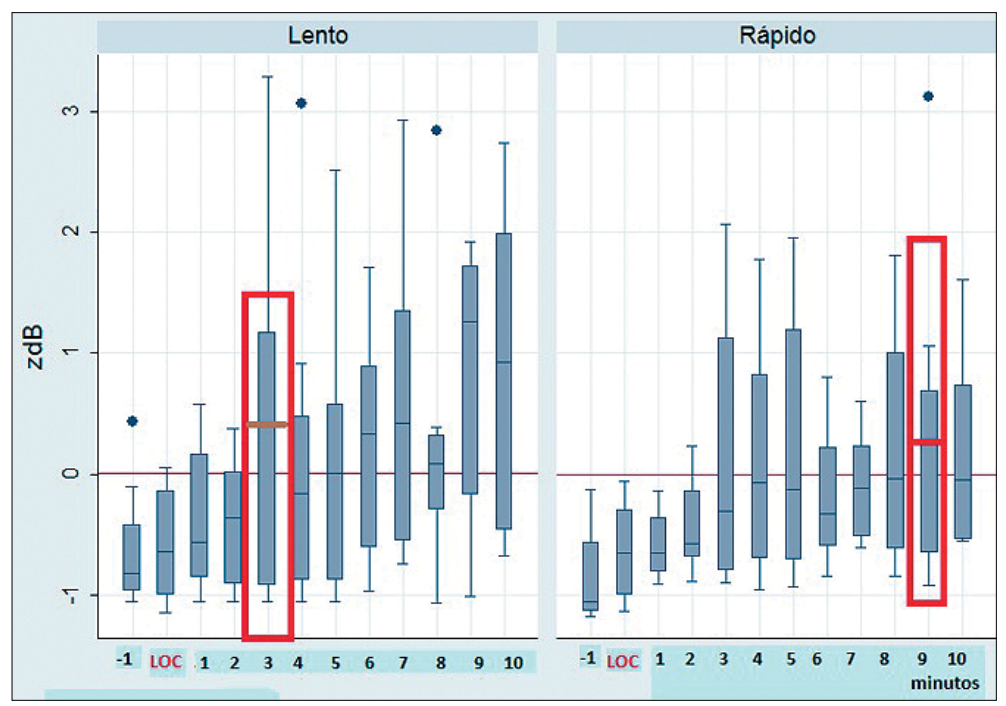

Figura 1. Medianas de poder alfa por grupo $(\mathrm{zdB})$ para cada minuto tras la inconciencia (LOC). 
fueron de 2,6 (sd 0,44) para GL y 4,8 (sd 0,76) $\mathrm{ug} / \mathrm{ml}$ para GR $(\mathrm{t}=-6,78)$. Los valores promedio del PSI SEDLINE al momento del LOC fueron de 67 (sd 12) para GL y de 61 (sd 22) para GR, T student $=0,65$. El análisis de la banda alfa mostró que el poder espectral estandarizado fue globalmente menor en inducciones rápidas durante los 10 min tras LOC (zdB GL 0,12 vs GR -0,123 $\mathrm{t}=0,04$ ). El box plot (figura 1) muestra que a los 3 min en GL aparece una banda alfa significativa, pero a los 9 min en GR.
Conclusiones: En las inducciones lentas se observa mayor poder espectral de la banda alfa y una instalación de la condición estereotipada, que define el estado anestésico, más precoz que en inducciones rápidas.

\section{Referencias}

1. The Journal of Neuroscience, January 15, 2014 • 34(3):839-845-839.

2. Anesthesiology 1999; 90:92-7Ann Neurol 2005;58:585-593. 